\title{
OS PAPÉIS DO CLIENTE NOS SERVIÇOS: UMA DISCUSSÃO ACERCA DAS POSSIBILIDADES DE PARTICIPAÇÃO DO CLIENTE NA CRIAÇÃO DE VALOR E MELHORIA DA QUALIDADE
}

\section{THE CUSTOMER ROLES IN SERVICES: A DISCUSSION ABOUT THE POSSIBILITIES OF CUSTOMER PARTICIPATION IN VALUE CREATION AND QUALITY IMPROVEMENT}

\author{
Noel Torres Júnior ${ }^{\text {; Dario Ikuo Miyake }}{ }^{2}$; \\ ${ }^{1}$ Universidade Federal de Minas Gerais - UFMG - Belo Horizonte - Brasil \\ noel@face.ufmg.br \\ ${ }^{2}$ Universidade de São Paulo - USP - São Paulo - Brasil \\ dariomiy@usp.br
}

\begin{abstract}
Resumo
Vários trabalhos têm demonstrado a importância da maior participação do cliente nos processos produtivos como um meio para o aumento da qualidade elou produtividade dos serviços. Envolver os clientes nos serviços impõe a necessidade de se discutir os papéis que ele pode desempenhar. Nesta direção, alguns autores advogam a necessidade das empresas implementarem novos papéis de clientes que propiciem também uma efetiva agregação de valor ao próprio negócio. Neste sentido, algumas empresas buscam não apenas um maior conhecimento acerca dos seus clientes, mas também objetivam a aquisição do conhecimento dos mesmos. Diante desta nova realidade, o presente trabalho explora os diferentes papéis que o cliente pode desempenhar nos serviços. Onze diferentes papéis foram identificados: cliente como agente de inovação, comprador, competidor para o serviço, co-produtor, concorrente ou parceiro de outros clientes, instrutor, recurso para o processo, usuário, auditor, produto do processo e promotor do serviço. As diferentes estratégias existentes na literatura de marketing e de operações de serviços para o provedor efetivar e/ou aperfeiçoar a participação dos mesmos são também apresentadas. Finalmente, este artigo apresenta resultados de estudos de casos conduzidos em organizações que processam os próprios clientes em que várias destas estratégias foram identificadas e são discutidas.
\end{abstract}

Palavras-chave: Papéis dos clientes; Operações de Serviços; Criação de Valor.

\section{Introdução}

Em um trabalho pioneiro na área, Chase (1978) propôs a classificação dos diferentes serviços utilizando a variável grau de contato do cliente com o sistema. Esta dimensão baseia-se no tempo de contato do primeiro com o segundo. Mais especificamente, refere-se ao percentual dado pelo período em que o cliente permanece em contato com o sistema em relação ao prazo total necessário para realizar esse processo. Os sistemas podem ser classificados como serviços puros 
(alto contato), mistos (médio contato) ou quase manufatura (baixo contato). Considerando esta variável, Chase (1978) defende que as organizações de serviço diminuam o tempo de contato com os clientes para aumentarem sua eficiência produtiva. Nesta direção, Levitt (1972) defende a chamada "Abordagem da Linha de Produção" em que a maior participação do cliente no processo prejudica a eficiência produtiva do sistema de prestação de serviço. Os defensores desta abordagem argumentam que o sistema de prestação de serviços deveria ser isolado ao máximo dos clientes, a fim de reduzir a incerteza que eles podem introduzir no processo produtivo, haja vista a influência que teriam no cumprimento dos prazos e a dificuldade de controlar suas atitudes e ações. Entretanto, vários trabalhos posteriores mostraram a importância da maior participação do cliente nos processos produtivos (LOVELOCK e YOUNG, 1979; BOWEN, 1986; MILLS e MORRIS, 1986). Recentemente, alguns autores têm advogado a necessidade de uma maior participação do cliente, não apenas agindo como um "co-produtor", mas atuando em novos papéis (cliente como um inovador, cliente como promotor do serviço, etc.) para que a empresa consiga, com a maior participação do mesmo, oferecer-lhe efetivamente mais valor (WIKSTRÖM, 1996; PRAHALAD e RAMASWAMY, 2000; VON HIPPEL, 2001).

Diante desta nova realidade, o presente trabalho explora os diferentes papéis que o cliente pode desempenhar nos serviços. A atuação do cliente em certos papéis até promove a efetiva realização do processo de serviço e deveria ser estimulada. Assim sendo, o trabalho também apresenta as diferentes estratégias consideradas na literatura de marketing e de operações de serviços para o provedor efetivar e/ou aperfeiçoar a participação dos mesmos. Finalmente, este artigo apresenta resultados de estudos de casos conduzidos em organizações que processam os próprios clientes em que várias destas estratégias foram identificadas e analisadas.

\section{Métodos e Técnicas de Pesquisa}

Este trabalho consiste em uma pesquisa de caráter exploratório que emprega a abordagem de estudo de caso. A realização de um estudo exploratório é recomendada quando o conhecimento sobre o problema ou fenômeno objeto de estudo ainda é reduzido. De acordo com Yin (2001), o estudo de caso é indicado para pesquisas que analisam um fenômeno contemporâneo em um contexto real. Assim, o encaminhamento metodológico deste trabalho se justifica pela carência de estudos sobre o tema e pelo foco no modo e circunstâncias em que um fenômeno ocorre na prática em empresas.

Yin (2001) sugere que o estudo de caso é particularmente apropriado quando a pergunta de pesquisa concentra-se em "como" e "por quê" os fenômenos observados acontecem, quando não há 
necessidade de controle sobre o comportamento dos eventos, e quando o enfoque estiver em eventos contemporâneos.

O estudo realizado não requereu controle sobre os acontecimentos e focalizou os papéis adotados pelos clientes nas empresas pesquisadas procurando melhor compreendê-los. Mais especificamente, utilizou-se a metodologia de múltiplos casos. A opção por esta abordagem deve-se à pretensão de obter resultados e conclusões que não sejam específicos a um particular caso e que tenham a possibilidade de serem considerados numa gama mais ampla de organizações. A possibilidade de estender os achados do estudo àquelas organizações que compartilham características comuns favorece sua validade interna no contexto do tipo de organização a que pertencem os casos contemplados (McCUTCHEON e MEREDITH, 1993). O desenvolvimento do presente trabalho apoiou-se no estudo de uma amostra constituída de quatro casos em empresas que têm como objeto principal do processo as próprias pessoas e que envolvem cada cliente diretamente na entrega dos serviços. Este tipo de serviço, segundo a literatura consultada, permite uma maior participação do cliente no processo de prestação de serviços possibilitando a verificação de um grande número dos papéis que o cliente pode desempenhar em serviços.

A coleta de dados foi efetuada principalmente por meio de entrevistas semi-estruturadas com os gestores de operações dos serviços analisados. Utilizou-se um questionário semi-estruturado que direcionou a coleta de informações acerca dos principais processos existentes nas empresas para a entrega dos serviços, além de informações a respeito das atividades que são realizadas pelos clientes no que se concerne aos possíveis papéis que eles podem desempenhar nos serviços. As entrevistas foram complementadas por outras fontes, como pesquisa bibliográfica, pesquisa documental e observação direta, procurando relacionar diferentes evidências.

\section{Referencial teórico}

\subsection{Papéis do Cliente}

A literatura destaca as características relativas ao envolvimento do cliente que são essenciais para sucesso da empresa, enfatizando o papel do cliente como um co-produtor, mas a participação do cliente não se restringe apenas a esse papel. A participação do cliente deve ser vista de modo mais amplo, podendo ser entendida como o nível de participação requerido do próprio cliente por meio de seu engajamento em uma ou mais atividades específicas do serviço. Portanto, a participação do cliente é dependente do tipo de serviço e das suas necessidades. É determinada pelo(s) papel(éis) que o cliente deseja ou aceita desempenhar dentro do processo de serviço. O espectro de envolvimento do cliente varia de uma participação passiva até um dado grau em que o 
serviço é quase que completamente conduzido pelo próprio cliente (GRAF, 2007). A revisão da literatura indicou vários papéis que o cliente pode desempenhar nos serviços e cada um deles é descrito a seguir.

\subsubsection{Cliente como agente de inovação}

A empresa pode também envolver o cliente no planejamento das atividades do serviço que será oferecido, solicitando suas idéias e sugestões para a definição das atividades que compõem o processo de serviço (WIKSTRÖM, 1996). O know-how e competência dos clientes são transformados em novos serviços. Os clientes do tipo lead-users desempenham um papel importante neste processo. As empresas podem buscar ativamente inovações desenvolvidas por estes usuários. A empresa é capaz de identificar este tipo de cliente pelo tipo de suporte que eles solicitam e pela qualidade dos seus questionamentos. A empresa pode também solicitar que os seus clientes definam o que esperam que o serviço faça para eles. Os resultados esperados do serviço relatados pelos clientes fornecem oportunidades para o desenvolvimento de novos serviços (ULWICK, 2002).

\subsubsection{Cliente como comprador}

Neste papel, o cliente define a aquisição do serviço. Atributos como análise, experiência e credibilidade levam os clientes a decidirem pelo serviço A ou B (HOFFMAN e BATESON, 2003).

Tornar o cliente um comprador permanente traz vários benefícios para a empresa. Neste sentido, Lovelock e Wright (2002) observam que são vários os ganhos advindos da retenção dos clientes. Quanto mais um cliente permanece com uma empresa, mais lucrativo é servi-lo. Além disso, os custos iniciais para atrair clientes fiéis podem ser amortizados no decorrer de um período mais longo que pode se estender a muitos anos. Há quatro fatores que trabalham a favor do fornecedor de serviços na obtenção de lucros crescentes por meio da fidelização do cliente: i) lucro derivado do aumento das compras; ii) lucro por redução de custos operacionais; iii) lucro por indicações de outros clientes; e iv) lucro por preço superior. Os benefícios econômicos da lealdade de seus clientes freqüentemente explicam por que uma empresa é mais lucrativa do que uma concorrente. 


\subsubsection{Cliente como competidor para o serviço}

Um papel que também pode ser protagonizado pelos clientes é o de competidor potencial. Em muitas situações, tanto indivíduos como empresas têm a escolha de comprar serviços na esfera comercial ou de eles próprios produzirem o serviço - completamente ou de maneira parcial. Portanto, de certo modo, podem ser competidores das empresas que fornecem o serviço (BITNER et al., 1997).

\subsubsection{Cliente como co-produtor}

O cliente pode assumir a execução de várias atividades do processo de entrega do serviço no lugar dos funcionários. Neste papel, o cliente é mobilizado como um recurso produtivo, ou seja, como um "funcionário parcial" (BOWEN, 1986; MILLS e MORRIS, 1986). Vários incentivos podem ser identificados quando o clinte participa como co-produtor:

- Preços mais baixos, uma vez que a empresa pode obter redução de custo com o uso mais eficiente dos recursos mobilizados;

- A auto-estima é elevada por causa do aumento de controle por parte do cliente;

- O próprio cliente passa a ter mais discrição e oportunidades para fazer escolhas;

- Os tempos de espera podem ser reduzidos;

- Possibilita maior personalização do serviço (LENGNICK-HALL,1996).

Para que a participação do cliente seja bem-sucedida, Bowen (1986) realça a importância de orientá-lo e treiná-lo adequadamente para a execução de suas tarefas, assegurando que seja capaz de executá-las. Isso implica também na empresa definir de forma consistente e clara que tarefas e como elas deverão ser realizadas pelo cliente.

\subsubsection{Cliente como concorrente ou parceiro de outros clientes}

Em muitos serviços, a entrega não é feita somente para um cliente. Os clientes, muitas vezes, interagem com outros durante esse processo. Essa situação ocorre porque eles recebem o serviço simultaneamente com outros, ou porque devem esperar a sua vez, enquanto outros estão recebendo atendimento. Nesses casos, os outros clientes podem afetar positivamente ou negativamente a natureza dos resultados. Trabalhos como de Bitner et al. (1997), Grove e Fisk (1997) e Zeithaml e Bitner (2003) realçaram este aspecto. Neste papel, um cliente pode colaborar com outro ou agir de modo indesejável. Além disso, ele ainda pode competir com terceiros pelos 
recursos oferecidos pelo prestador de serviço (TORRES JÚNIOR, 2007). Vários textos de marketing de serviços reportam a existência de clientes "abusivos", que normalmente prejudicam a experiência sobre o serviço de outros clientes.

Já em alguns serviços é desejável mais interação e aproximação entre os diferentes clientes. Nesta situação, a empresa deve buscar meios para promover mais socialização entre eles, utilizando, por exemplo, a estratégia de promoção de eventos sociais (ZEITHAML e BITNER, 2003).

\subsubsection{Cliente como instrutor}

Em serviços intensivos de conhecimento, como atividades de consultoria empresarial, o cliente acaba "ensinando" os funcionários do provedor de serviço. Este aprendizado, por parte do provedor, se faz necessário para que o serviço seja entregue de acordo com as necessidades do cliente (CHERVONNAYA, 2003).

Este papel exige boas habilidades de comunicação para instruir ou orientar o provedor de serviço, como também assegurar que o conhecimento seja efetivamente transferido para o provedor. O cliente terá que definir que partes de seu conhecimento tecnológico e/ou organizacional podem ser transferidas e que partes devem ser mantidas em segredo (CHERVONNAYA, 2003).

\subsubsection{Cliente como recurso do processo}

O cliente pode fornecer diferentes fatores de produção, por exemplo: informação, dinheiro, idéias, material a ser processado. Em alguns serviços, além de tais fatores, o próprio cliente pode ser o input que irá passar por uma transformação (LENGNICK-HALL, 1996).

As informações provenientes dos clientes são importantes para o planejamento do serviço. Informações incompletas ou erradas podem levar a atrasos, retrabalhos ou mesmo a falhas na execução do serviço pretendido. Portanto, a empresa deve buscar meios para que todas as informações necessárias sejam coletadas e estejam corretas.

\subsubsection{Cliente como usuário}

Neste papel, o cliente recebe diretamente o serviço e se beneficia dele. Como usuário, define dois resultados importantes. Primeiro, percebe e mede a discrepância entre suas expectativas e a experiência de serviço recebida e então determina seu nível de satisfação (ZEITHAML e BITNER, 2003). 


\subsubsection{Cliente como auditor}

O cliente pode agir como um "auditor" quando for capaz de julgar a qualidade do serviço recebido. Neste papel ele avalia o serviço recebido o que requer capacidades relacionadas à habilidade de julgar a qualidade de serviço. Um bom auditor é uma pessoa que é treinada para observar (estar atento aos detalhes), deve ter conhecimento do serviço, capacidade de pensar analiticamente e articular suas idéias claramente e de modo convincente. Dependendo das características do serviço em questão, algumas destas habilidades se tornam mais importantes que outras. Por exemplo, para serviços relativamente simples (uma pequena viagem de ônibus), a capacidade de observação pode ser suficiente, já em serviços como a implementação de um certo sistema de informação numa empresa exige do cliente um grande conhecimento em informática (CHERVONNAYA, 2003).

\subsubsection{Cliente como um produto do processo}

Trata-se de uma situação em que o produto - resultado buscado pelo processo de entrega do serviço - é a mudança de comportamento ou atitudes por parte do cliente ou a modificação de uma dada condição do cliente para outra. O resultado esperado depende do interesse do próprio cliente em mudar. $\mathrm{O}$ cliente tanto no papel de comprador como no de usuário, pode afetar o resultado na medida em que ele deve se interessar pelo serviço e realizar de modo adequado suas atividades. (LENGNICK-HALL, 1996).

\subsubsection{Cliente como promotor do serviço}

Quando os clientes são capazes de atuar como auditores, eles podem atuar também na promoção do serviço passando uma imagem positiva ou negativa do serviço para outras pessoas apoiando-se nesta capacidade de avaliação (CHERVONNAYA, 2003).

Habilidades de comunicação são vitais para atuar neste tipo de papel. Isto significa que o cliente deve ser capaz de:

- Selecionar os clientes adequados para divulgar sua opinião;

- Deve também saber escolher a hora e o lugar adequados para realizar a divulgação do serviço;

- Deve ser convincente ao divulgar o serviço (ter uma boa capacidade de argumentação); 
- Na divulgação pela web, deve ser capaz de lidar com tecnologia da informática (CHERVONNAYA, 2003).

\subsection{Papéis do Cliente sob a ótica do processo}

Segundo a literatura de gerenciamento de operações de serviços, os serviços podem ser melhor entendidos sob a ótica de um processo de transformação. Nesta direção, vários autores utilizam um modelo de transformação para descrever a criação dos serviços. Genericamente um modelo deste tipo contempla, sob a dimensão temporal, três grandes fases:

- Pré-processamento: envolve basicamente a escolha do serviço, sua solicitação pelo cliente e o seu planejamento pelo provedor e/ou cliente;

- Processamento do serviço: envolve a entrega do serviço ao cliente. Três elementos se fazem presentes nesta fase: input, processo e output;

- Pós-processamento: nesta fase o provedor finaliza sua entrega e o cliente recebe finalmente o output do serviço.

Figura 1 - Possíveis papéis do cliente e respectivas fases do serviço

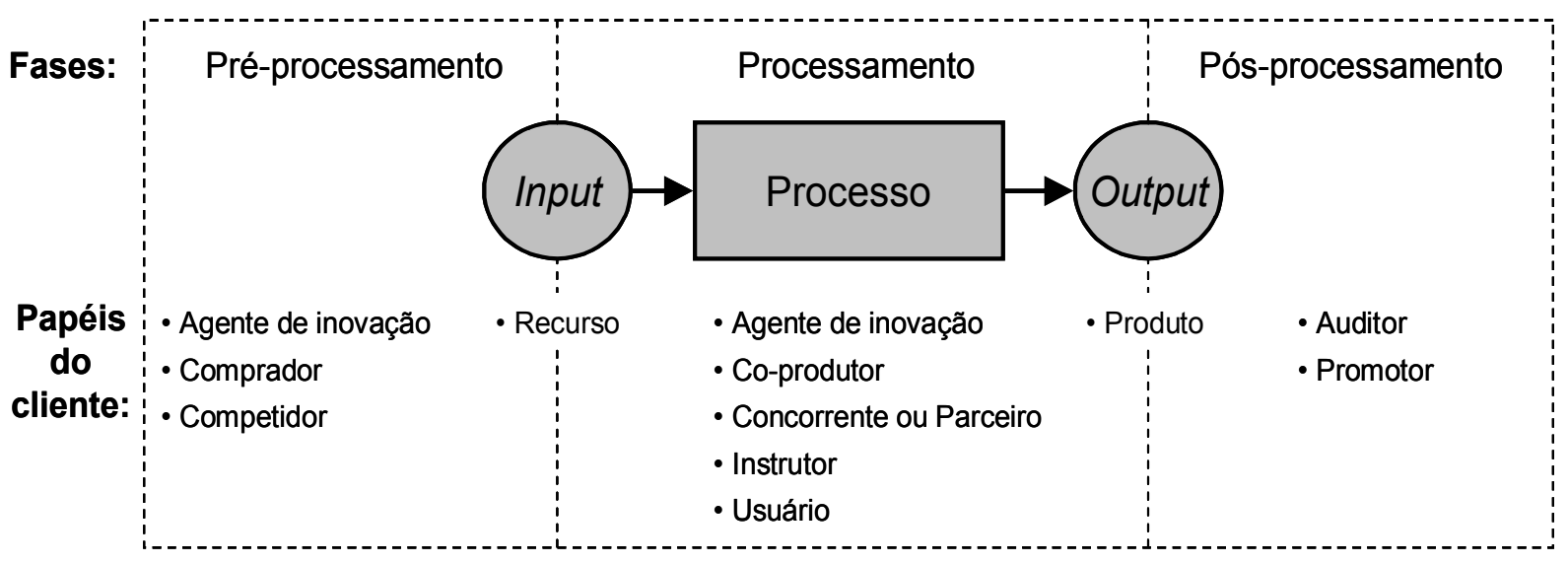

O contexto em que os diferentes papéis apresentados anteriormente são exercidos é delimitado em função das três grandes fases que compõem o processo de serviços. A Figura 1 posiciona os possíveis papéis dos clientes nestas fases.

Quadro 1 - Papéis do cliente e principais táticas que promovem maior participação dos clientes

\begin{tabular}{|c|l|}
\hline Papéis do cliente & \multicolumn{1}{c|}{ Táticas que promovem maior participação dos clientes } \\
\hline $\begin{array}{c}\text { Agente de } \\
\text { inovação }\end{array}$ & $\begin{array}{l}\text { Implementar programas que capturem as inovações desenvolvidas pelos clientes. } \\
\text { Estruturar o processo de serviço para que ocorra o envolvimento do cliente no planejamento do } \\
\text { serviço. }\end{array}$ \\
\hline Comprador & $\begin{array}{l}\text { Implementar programas de fidelidade. } \\
\text { Instituir garantias de serviço. }\end{array}$ \\
\hline
\end{tabular}




\begin{tabular}{|c|c|}
\hline & Planos com descontos conforme o tempo ou freqüência de uso. \\
\hline Competidor & $\begin{array}{l}\text { Informar o cliente sobre as vantagens do serviço oferecido em relação ao "serviço faça você } \\
\text { mesmo" }\end{array}$ \\
\hline Co-produtor & $\begin{array}{l}\text { Orientar e treinar adequadamente o cliente para a execução das suas tarefas, assegurando que seja } \\
\text { capaz de executá-las. } \\
\text { Fornecer antecipações realistas sobre o serviço, como um meio de tornar os clientes cientes de } \\
\text { seus papéis de co-produção. } \\
\text { Premiar ou recompensar a participação do cliente. }\end{array}$ \\
\hline $\begin{array}{l}\text { Concorrente ou } \\
\text { parceiro dos outros } \\
\text { clientes }\end{array}$ & $\begin{array}{l}\text { Como meio para inibir comportamentos indesejáveis, a empresa pode: i) definir regras de conduta } \\
\text { que devem ser respeitadas pelos clientes quando utilizam os serviços; ii) implementar } \\
\text { programas de educação e orientação (aulas formais, folhetos, placas de orientação, etc.); iii) } \\
\text { recompensar os clientes pelo bom comportamento ou puni-los pelo mau comportamento; iv) } \\
\text { administrar o composto de clientes de forma que segmentos conflitantes não se misturem. } \\
\text { Muitas vezes, é desejável mais interação e aproximação entre os diferentes clientes. Nesta } \\
\text { situação, a empresa deverá realizar atividades como festas, excursões e passeios para } \\
\text { promover maior socialização entre os clientes. }\end{array}$ \\
\hline Instrutor & Recompensar a maior participação dos clientes nestes papéis. \\
\hline $\begin{array}{l}\text { Recurso do } \\
\text { processo }\end{array}$ & $\begin{array}{l}\text { Segmentar o mercado, buscando clientes com características compatíveis (horário, preferências, } \\
\text { perfil sócio-econômico, etc.) } \\
\text { Informar e educar o cliente quanto à importância e ao tipo de informações que são necessárias } \\
\text { para se iniciar o processo de entrega do serviço }\end{array}$ \\
\hline Auditor & $\begin{array}{l}\text { Disponibilizar instrumentos adequados (formulários, sites, etc) para o cliente realizar a avaliação } \\
\text { do serviço. } \\
\text { Premiar ou recompensar a participação do cliente como auditor. }\end{array}$ \\
\hline Usuário & $\begin{array}{l}\text { Estabelecer uma comunicação eficiente com o cliente, disponibilizando informações relevantes } \\
\text { sobre o serviço, como programação, preços, instruções para o uso dos serviços, lembretes, } \\
\text { avisos, notificação de mudanças, etc. } \\
\text { Prover suporte ao cliente durante a realização das atividades, orientando, esclarecendo dúvidas e } \\
\text { estimulando sua participação }\end{array}$ \\
\hline $\begin{array}{l}\text { Produto do } \\
\text { processo }\end{array}$ & --- \\
\hline Promotor & ção do cliente como promotor. \\
\hline
\end{tabular}

Fonte: Lovelock (1995); Lovelock e Wright (2002); Lengnick-Hall (1996); Zeithaml e Bitner (2003); Wikström (1996); Graf (2007).

\subsection{Promovendo a participação do Cliente}

Sob o ponto de vista da operação de serviços, as empresas devem compreender quais papéis os clientes podem desempenhar e devem promover aqueles papéis que levarão a uma melhoria da qualidade e produtividade dos serviços. É importante ressaltar que os papéis não podem ser vistos como entes independentes, pois existem interações entre eles. Por exemplo, o papel do cliente enquanto comprador dependerá da percepção da qualidade do serviço que é influenciada pela avaliação realizada pelo cliente no papel de auditor. O Quadro 1 indica as principais táticas reportadas na literatura que promovem a maior participação dos clientes. 


\section{Pesquisa de campo}

\subsection{Os serviços analisados no trabalho}

O desenvolvimento do presente trabalho apoiou-se no estudo de um conjunto constituído de quatro casos, em diferentes organizações. No sentido de permitir uma melhor confrontação dos dados coletados, foram pesquisadas empresas de dois tipos de serviço. A amostra investigada é formada por duas academias de ginástica e dois cursos preparatórios para concursos. Esses serviços apresentam algumas características em comum:

- Processam pessoas e o cliente realiza também o papel de produto do serviço. Ou seja, na academia o cliente almeja uma mudança em si mesmo, por exemplo, o seu emagrecimento. Nos cursos preparatórios o cliente almeja o domínio do conhecimento sobre o conteúdo que será cobrado no exame do concurso que pretende prestar;

- Ao contrário do que ocorre em muitos tipos de serviços, os serviços não se finalizam com um único encontro de serviço. Dependem de vários encontros para que os resultados almejados pelos clientes sejam alcançados. Isso, de certo modo, evidencia a necessidade do estabelecimento de um relacionamento entre o provedor de serviço e o cliente, devido à interdependência entre os diferentes encontros e, por conseqüência, a necessidade de sua continuidade;

- Os resultados almejados pelos clientes dependem da freqüência e da maneira como o cliente participa do processo de entrega do serviço. Por exemplo: o emagrecimento almejado pelo cliente ao freqüentar uma academia de ginástica, depende, em grande parte, do rigor no cumprimento das atividades físicas previstas em sua ficha diária de treinamento. O resultado será obtido pelo efeito cumulativo dessas atividades ao longo do tempo.

As características expostas acima indicam que todos os papéis discutidos no referencial teórico podem estar presentes nas empresas.

\subsection{Os resultados encontrados em campo}

A maioria dos papéis identificados na literatura consultada se fez presente na pesquisa de campo realizada. A atuação do cliente em nove dos onze papéis levantados pôde ser verificada. E isso foi constatado tanto nas academias de ginástica como nos cursos preparatórios. Apenas os papéis do cliente como instrutor e competidor do serviço não puderam ser examinados. Em relação à forma de exercício dos papéis que foram observados, vale destacar os seguintes aspectos: 
a) Cliente como agente de inovação: Nas academias de ginástica o cliente pode executar este papel ao dar sugestões sobre o serviço em si e quando sugere alterações na sua ficha de treinamento, durante a reavaliação física e fisioterápica. Nos cursos preparatórios o cliente pode executar este papel ao dar sugestões sobre o serviço nas avaliações referentes à qualidade do serviço realizadas periodicamente pelas duas empresas pesquisadas;

b) Cliente como comprador do serviço: Este papel foi observado em todos os casos pesquisados, pois refere-se a tipos de serviço em que o próprio cliente seleciona os serviços que atendem suas necessidades (Ex: escolha do tipo de ginástica que irá exercitar; escolha do assunto e abrangência do curso, escolha da carga horária, escolha do período de ministração, etc.);

c) Cliente como co-produtor: Nas academias de ginástica e nos cursos preparatórios o cliente executa este papel em vários momentos, durante a entrega do serviço. São exemplos: passagem do cartão de identificação na entrada ou saída das academias, ajudando a registrar dados essenciais ao controle da sua freqüência; preenchendo os formulários para matrícula; realizando provas simuladas pela Internet nos cursos preparatórios, etc.;

d) Cliente como concorrente ou parceiro de outros clientes: Este papel se faz mais presente nos horários de maior movimento, momento no qual o cliente normalmente necessita concorrer com outros clientes pelo uso de alguns recursos do serviço. Também neste período, o cliente poderá receber ajuda ou incentivo dos outros clientes. São exemplos de situação em que o cliente concorre com os outros: a espera pela disponibilidade de aparelhos de musculação para se exercitar nas academias de ginástica; a espera pela liberação de uma sala de estudo ou por um livro que já está emprestado, etc. São exemplos de situação em que o cliente atua como parceiro dos outros: nas aulas de ginástica em grupo, cada cliente auxilia o outro na execução de exercícios de alongamento; durante atividades de musculação, um cliente pode ajudar o outro no ajuste dos aparelhos; durante o estudo em grupo, um cliente pode esclarecer dúvidas sobre determinado assunto nos cursos preparatórios, etc.;

e) Cliente como recurso do processo: Nos serviços analisados o cliente executa este papel ao fornecer informações para efetivação de sua matrícula. Em academias de ginástica, o cliente se torna recurso durante a avaliação física e fisioterápica;

f) Cliente como auditor: O cliente cumpre este papel nas academias de ginástica ao responder as pesquisas de avaliação da qualidade do serviço e durante as re-avaliações física e fisioterápica nas quais verifica os resultados obtidos com o serviço. Nos cursos preparatórios, o cliente participa como auditor quando responde as pesquisas de avaliação da qualidade do serviço e, durante as avaliações ou testes simulados, verifica o ganho de conhecimento obtido. O resultado obtido nos concursos serve também como um critério de avaliação do serviço pelo aluno; 
g) Cliente como usuário: Tanto na realização de exercícios de ginástica como em aulas de cursos preparatórios, o próprio cliente se faz presente no processo de serviço desempenhando este papel;

h) Cliente como promotor do serviço: Nos cursos preparatórios verificou-se que as empresas divulgam os nomes dos alunos aprovados nos concursos e em algumas delas o testemunho de alguns deles é também veiculado; Em academias de ginástica, o cliente participa de caminhadas, festas e pequenos eventos, momento no qual divulga o nome da academia em locais públicos;

i) Cliente como produto do processo: Nas academias de ginástica o ganho obtido pelo cliente com relação aos seus objetivos propostos (exemplos típicos: hipertrofia geral intensa, reabilitação muscular, definição muscular, relaxamento, alívio de dores, flexibilidade, emagrecimento, condicionamento físico e correção postural) indica que o próprio cliente é o recurso transformado e o produto do serviço. Nos cursos preparatórios a aprovação nos concursos e um bom rendimento nas avaliações indicam o ganho de conhecimento obtido pelo aluno que é ao mesmo tempo recurso transformado e o produto do serviço.

Nos casos investigados, não foi verificada a participação do cliente em processos de serviço de academias ou cursos preparatórios desempenhando os seguintes dois papéis:

j) Cliente como instrutor: A literatura consultada indica que este papel se faz mais presente em empresas intensivas em conhecimento onde há necessidade de troca de informações entre o cliente a empresa para a realização dos serviços. Um exemplo típico deste tipo é uma atividade de consultoria organizacional.

k) Cliente como competidor: Trata-se de um papel que existe nos tipos de serviço contemplados, mas não pode ser verificado nesta pesquisa. As academias de ginástica concorrem com os aparelhos domésticos de musculação que possibilitam a realização do serviço na própria residência dos clientes e os alunos dos cursos preparatórios têm a alternativa de realizar a preparação para os concursos de maneira individual. O papel do cliente como competidor do serviço não pode ser examinado na medida em que para sua consideração seria necessário obter dados com os usuários e não usuários dos serviços pesquisados e, no presente trabalho, a coleta de dados foi efetuada principalmente por meio de entrevistas semi-estruturadas com os gestores de operações dos serviços analisados.

Enxergando o cliente como um elemento que pode participar do processo de serviço contribuindo na melhoria da qualidade e produtividade do sistema, a gerência de empresas de serviço pode implementar mecanismos que promovam uma inserção mais participativa dos clientes. Nos estudos de casos realizados, procurou-se analisar como a gerência das empresas pesquisadas tem buscado esta forma de participação. 
Quadro 2 - Principais táticas utilizadas pelas empresas pesquisadas que promovem maior participação dos clientes

\begin{tabular}{|c|c|c|}
\hline $\begin{array}{l}\text { Papéis do } \\
\text { cliente }\end{array}$ & Academias de Ginástica & Cursos Preparatórios \\
\hline $\begin{array}{l}\text { Agente de } \\
\text { inovação }\end{array}$ & $\begin{array}{l}\text { Ficha de treinamento que prescreve os exercícios } \\
\text { a serem feitos pelo cliente é elaborada com a } \\
\text { sua participação. }\end{array}$ & $\begin{array}{l}\text { Analisa os resultados das avaliações do curso } \\
\text { realizadas pelo aluno para ajustar e/ou } \\
\text { modificar o curso. }\end{array}$ \\
\hline Comprador & $\begin{array}{l}\text { Descontos pelo tipo de plano: trimestral, } \\
\text { semestral ou anual incentivando uma maior } \\
\text { permanência no serviço. }\end{array}$ & $\begin{array}{l}\text { Descontos pelo tipo de plano escolhido, } \\
\text { incentivando uma maior permanência no } \\
\text { serviço. }\end{array}$ \\
\hline Competidor & Não foi verificada & Não foi verificada \\
\hline Co-produtor & $\begin{array}{l}\text { Acompanhamento pelos monitores das atividades } \\
\text { realizadas pelos alunos para assegurar que os } \\
\text { clientes sejam capazes de executar as } \\
\text { atividades de co-produção como ajuste de } \\
\text { aparelhos. }\end{array}$ & Não encontrada. \\
\hline $\begin{array}{l}\text { Concorrente } \\
\text { ou parceiro de } \\
\text { outros clientes }\end{array}$ & $\begin{array}{l}\text { Realização de caminhadas, festas e gincanas para } \\
\text { promover uma maior socialização dos } \\
\text { clientes. } \\
\text { Estabelecimento de regras de condutas e/ou } \\
\text { comportamento para inibir o mau } \\
\text { comportamento dos clientes. }\end{array}$ & $\begin{array}{l}\text { São promovidas festas de confraternização. } \\
\text { Estabelecimento de regras de condutas e/ou } \\
\text { comportamento para inibir o mau } \\
\text { comportamento dos clientes. }\end{array}$ \\
\hline Instrutor & Não encontrada. & Não encontrada. \\
\hline $\begin{array}{l}\text { Recurso do } \\
\text { processo }\end{array}$ & $\begin{array}{l}\text { Procedimento de diagnóstico (avaliações física e } \\
\text { fisioterápica) para todos os clientes } \\
\text { assegurando a coleta correta de informações } \\
\text { sobre os clientes. }\end{array}$ & Não encontrada. \\
\hline Auditor & $\begin{array}{l}\text { Sistema de avaliação física e fisioterápica é } \\
\text { incentivado a ser realizado com todos os } \\
\text { clientes em bases trimestrais. }\end{array}$ & $\begin{array}{l}\text { Sistema de avaliação do serviço realizado com } \\
\text { todos os clientes. }\end{array}$ \\
\hline Usuário & $\begin{array}{l}\text { Acompanhamento pelos monitores da realização } \\
\text { dos exercícios feitos pelos alunos durante as } \\
\text { atividades físicas fornecendo suporte e } \\
\text { incentivo à realização das mesmas. }\end{array}$ & $\begin{array}{l}\text { Monitoramento da freqüência do cliente, } \\
\text { induzindo indiretamente sua participação. } \\
\text { Suporte aos alunos por meio de monitores e } \\
\text { amplo acesso a vários tipos de informações } \\
\text { no site da empresa. }\end{array}$ \\
\hline Promotor & Não encontrada. & $\begin{array}{l}\text { Os nomes dos ex-alunos/alunos aprovados são } \\
\text { divulgados pela empresa. } \\
\text { Alguns ex-alunos que passaram em concursos são } \\
\text { convidados a dar um pequeno testemunho ou } \\
\text { mensagens que são divulgadas pela empresa. }\end{array}$ \\
\hline
\end{tabular}

O Quadro 2 sintetiza as principais táticas utilizadas pelas empresas pesquisadas para a promoção de uma maior participação dos clientes. Observa-se que, em ambos tipos de empresas, o envolvimento dos clientes no planejamento do serviço é estimulado de forma incipiente, pois as sugestões dos clientes estão limitadas ao modo de entrega do serviço. Não foi constatada uma participação mais ampla do cliente no planejamento do serviço como um todo. 


\title{
5. Considerações finais
}

A pesquisa de campo evidenciou o exercício de nove papéis que o cliente pode realizar nos serviços e que afetam a qualidade e produtividade nos processos das organizações. $\mathrm{O}$ estudo também identificou na literatura e na pesquisa de campo várias estratégias que podem ser utilizadas pelas empresas para incentivar a maior participação dos clientes no serviço.

Com o acesso à grande quantidade de informações disponibilizada atualmente pelas diferentes ferramentas de tecnologia da informação, os clientes têm a possibilidade de ter ao seu alcance praticamente o mesmo nível de informação que as empresas. Neste novo contexto, os clientes podem ser vistos como uma fonte de competências por deterem um certo know-how sobre o serviço, além de novos conhecimentos específicos que podem ser agregados ao serviço. Nesta direção, os clientes tendem a se tornar agentes importantes para a divulgação da imagem das empresas a outros potenciais clientes, e podem influenciar no desenvolvimento destas demandando novas soluções ou serviços que irão requerer um avanço no conhecimento detido pelas empresas. Como bem destacam Gibbert, Leibold e Probst (2002), mais do que conhecer bem o cliente, atualmente as empresas necessitam capturar o conhecimento dos clientes e explorar este recurso para cativar e fidelizá-los.

Vale salientar que a "Abordagem da Linha de Produção", discutida na introdução deste trabalho, ignora várias possibilidades de utilizar o cliente como uma fonte de agregação de valor ao serviço ofertado, portanto as idéias aqui apresentadas nos levam a questionar a continuidade desta estratégia em vários serviços.

O estudo mais profundo dos papéis que o cliente pode desempenhar no serviço nos fornece alternativas que podem viabilizar uma melhoria da qualidade e produtividade nos processos de serviço, além de elevar o valor dos serviços entregues pelas organizações. Este trabalho procurou delinear a natureza destas alternativas e apontar as oportunidades de melhoria ou inovação que estas podem proporcionar a pesquisadores e gestores que estejam buscando novos referenciais teóricos e metodológicos para a concepção, planejamento, implementação e controle de operações de serviços.

\begin{abstract}
Several studies have discussed the importance of greater customer involvement in service processes in order to improve quality and productivity. The consideration of customer involvement in services entails the need to discuss the roles that the customer can play. In this context, this paper explores the different roles that the customer could undertake in services and points out a set of eleven roles identified in a literature review: customer as an agent of innovation, purchaser, competitor for the service provider, co-producer, rival of other customers or partner of them, instructor, resource for the process, user, auditor, result of the process, and advocate of the service. Different strategies to accomplish or improve customer participation are also presented. Finally, it presents case studies conducted in organizations where the strategies considered for the management of these roles are identified and discussed.
\end{abstract}

Key-words: Customer Roles; Service Operations; Value Creation. 


\section{Referências}

BITNER, M. J.; FARANDA, W. T.; HUBBERT, A. R.; ZEITHAML, V. A. Customer contributions and roles in service delivery. International Journal of Service Industry Management, v. 8, n. 3, p.193- 205, 1997.

\section{cross'ref}

BOWEN, D. E. Managing Customers as Human Resources in Service Organizations. Human Resource Management, v. 25, n. 3 , p. $371-383,1986$.

cross'ref

CHASE, R. B. Where does the customer fit in a service operation? Harvard Business Review, Nov./Dec., p. 137-42, 1978.

CHERVONNAYA, O. Customer role and skill trajectories in services, International Journal of Service Industry Management, v. 14, n. 3, p. 347-63, 2003.

cross'

GIBBERT, M.; LEIBOLD, M., PROBST, G. Five Styles of Customer Knowledge Management and How Smart Companies Use Them To Create Value, European Management Journal, v. 20, n. 5, p. 459-469, 2002.

cross'

GRAF, A. Changing roles of customers: consequences for HRM, International Journal of Service Industry Management, v. 18, n. 5, p. 491-50, 2007.

cross ${ }^{\text {ref }}$

GROVE, S. J.; FISK, R. P. The Impact of Others Customers on Service Experiences: A Critical Incident Examination of "Getting Along". Journal of Retailing, v. 73, n. 1, p. 63-85, 1997.

crossef

GWINNER, K. P.; GREMLER, D. D.; BITNER, M. J. Relational benefits in services industries: The customer's perspective. Academy of Marketing Science Journal, v. 26, n. 2, p. 101-114, 1998.

HOFFMAN, K. D.; BATESON, J. E. G. Princípios de marketing de serviços: conceitos, estratégias e casos. São Paulo: Pioneira Thomson Learning, 2003.

LARSSON, R.; BOWEN, D. E. Organization and Customer: Managing Design and Coordination of Services. The Academy of Management Review, v. 14, n. 2, p. 213-33, 1989.

cross ${ }^{\text {ref }}$

LENGNICK-HALL, C. A. Customer contributions to quality: a different view of the customer-oriented firm. The Academy of Management Review, v. 21, n. 3, p. 791-824, 1996.

cross ${ }^{\text {ref }}$

LEVITT, T. Production-Line Approach to Service. Harvard Business Review, Set.-Out., p. 41-52, 1972.

LOVELOCK, C. H.; WIRTZ, J. Marketing de Serviços: pessoas, tecnologia e resultados. São Paulo: Pearson Prentice Hall, 2006, 412 p.

LOVELOCK, C. H.; WRIGHT, L. Serviços: marketing e gestão. São Paulo: Saraiva, 2002, 416 p.

LOVELOCK, C. H.; YOUNG, R. F. Look to consumers to increase productivity. Harvard Business Review, May/June, p. 168-178, 1979.

MCCUTCHEON, D.M.; MEREDITH, J.R. Conducting case study research in operations management, Journal of Operations Management, v. 11, p. 239-256, 1993.

cross ${ }^{\text {ref }}$

MILLS, P. K.; MORRIS, J. H. Clients as Partial Employees of Service Organizations: Role Development in Client Participation. The Academy of Management Review, v. 11, n. 4, p. 726-735, 1986.

PRAHALAD, C.K.; RAMASWAMY, V. Co-opting customer competence, Harvard Business Review, 
January/February, p. 79-87, 2000.

TORRES JÚNIOR, N. Operações em Serviços de Resultados Ulteriores: diretrizes gerenciais para um melhor desempenho. 2007. 224 p. Tese (Doutorado). Departamento de Engenharia de Produção, Escola Politécnica, Universidade de São de Paulo. São Paulo, 2007.

ULWICK, A.W. Turn customer input into innovation, Harvard Business Review, January, p. 91-7, 2002.

VON HIPPEL, E. Innovation by user communities: learning from open-source software, MIT Sloan Management Review, Summer, p. 82-6, 2001.

WIKSTRÖM, S. The customer as co-producer. European Journal of Marketing, v. 30, n. 4, p. 6-19, 1996. cross'

YIN, R. K. Estudo de Caso: Planejamento e métodos. Porto Alegre: Bookman, 2002, 199 p.

ZEITHAML, V. A; BITNER, M. J. Marketing de serviços: a empresa com foco no cliente. Porto Alegre: Bookman, 2003, 536 p.

\section{Dados dos autores:}

Nome completo: Noel Torres Júnior

Filiação institucional: Faculdade de Ciências Econômicas da Universidade Federal de Minas Gerais

Departamento: Departamento de Ciências Administrativas (CAD)

Função ou cargo ocupado: Professor Adjunto

Endereço completo para correspondência (bairro, cidade, estado, país e CEP): Avenida Antônio

Carlos, 6627 - Pampulha - Belo Horizonte - MG - Brasil - CEP 31270-901

Telefones para contato: (31)3409-7316 - ramal 7316

e-mail:noel@face.ufmg.br

Nome completo: Dario Ikuo Miyake

Filiação institucional: Universidade de São Paulo, Escola Politécnica

Departamento: Departamento de Engenharia de Produção

Função ou cargo ocupado: Professor Assistente Doutor

Endereço completo para correspondência (bairro, cidade, estado, país e CEP): Avenida Prof. Almeida Prado, 128 - travessa 2 - Cidade Universitária - São Paulo - SP - Brasil - CEP 05508070

Telefones para contato: (11) 3091-5363 - ramal 427

e-mail: dariomiy@usp.br

Recebido para publicação em: 26/02/2009

Aceito para publicação em: 05/06/2009 